\title{
SAVONIUS ROTOR PROTOTYPE BASED ON WIND TUNNEL TESTING
}

\author{
N. H. Mahmoud ${ }^{1}$, A. A. El-Haroun ${ }^{1,}{ }^{*}$, E. Wahba ${ }^{1}$ and M. H. Nasef ${ }^{2}$ \\ ${ }^{1}$ Mechanical Power Engineering Department, Faculty of Engineering, \\ Shebin El-Kom, Minoufiya University, Egypt \\ ${ }^{2}$ Faculty of Engineering, Sinai University, Egypt \\ * Corresponding Author. E-mail: ah81256@yahoo.com, Fax:0020482235695
}

\begin{abstract}
In this work, it is planned to design and test a prototype of Savonius rotor in free wind based on the results of the previous experimental study. The prototype is designed and tested in El-Arish at the Faculty of Engineering, Sinai University. Although El-Arish has lower average yearly wind speed compared to other locations with higher average wind speed, like Hurghada. The results show that Savonius rotor prototype in El-Arish gives considerable efficiency and begins to give power at a relative low wind speed. While the energy generated from the Savonius rotor prototype in El-Arish is small, the cost of energy generated is competitive with other energy sources. The cost of $\mathrm{kW} \mathrm{hr}$ generated from Savonius rotor is expected to be very low specially in locations with high average wind speed. The majority of the Egyptian locations having an average wind speed between 3.5 and $4.5 \mathrm{~m} / \mathrm{s}$. The cost of kW.hr generated from Savonius rotor in these locations is expected to be between 0.42 and $0.28 \mathrm{LE}$. In locations where average wind speed is $6 \mathrm{~m} / \mathrm{s}$, the cost of $\mathrm{kW} \mathrm{hr}$ is expected to be $0.1 \mathrm{LE}$. Therefore the use of Savonius rotor will be attractive in many locations in Egypt and it can be used to pump water for irrigation of lands. This will save a great part of conventional energy sources used for this purpose and consequently reduces the environmental pollution.
\end{abstract}

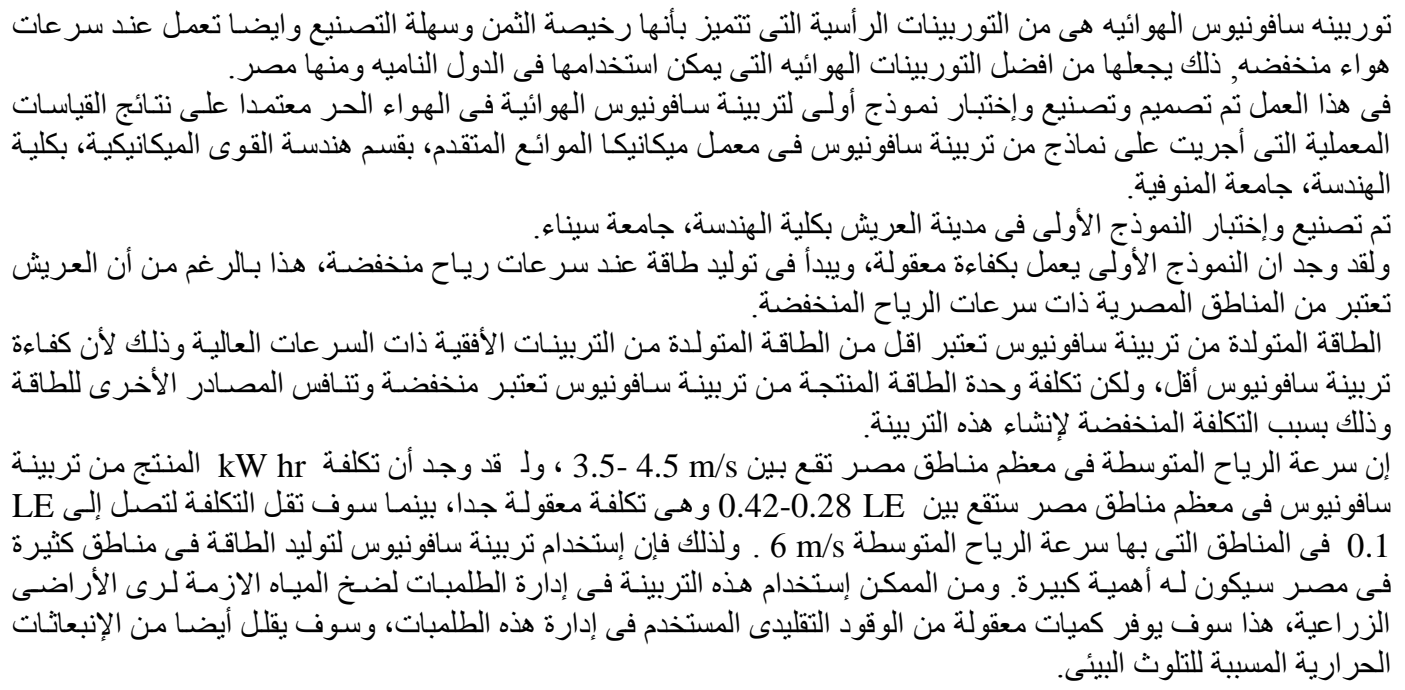

Keywords: Renewable energy, wind energy, vertical axis wind turbine, Savonius rotor, prototype.

\section{NOMENCLATURES}

A projected area for the rotor, $\mathrm{m}^{2}$

a shaft diameter, $m$

$\mathrm{C}_{\mathrm{p}} \quad$ power coefficient $=\mathrm{p}_{\mathrm{m}} / \mathrm{p}_{\mathrm{w}},---$

$\mathrm{D}$ diameter of the rotor, $\mathrm{m}$

$\mathrm{D}_{\mathrm{o}} \quad$ end plate diameter, $\mathrm{m}$ d diameter of the blade, $m$

e overlap distance, $\mathrm{m}$

$\mathrm{H}$ height of the rotor, $\mathrm{m}$

$\mathrm{p}_{\text {ave }}$ average power, $\mathrm{W}$

$\mathrm{p}_{\mathrm{m}} \quad$ mechanical power, $\mathrm{W}$

$\mathrm{p}_{\mathrm{w}} \quad$ wind power, $\mathrm{W}$

$T$ mechanical torque, N.m 


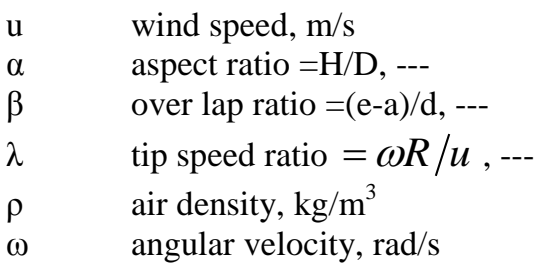

\section{INTRODUCTION}

It is a well-known fact that the world population increases rapidly from time to time, as a result of which energy consumption also increases. This increase in energy consumption comes parallel to the developments in technology and industry to meet the needs of the growing human population. Another fact known to us apparently but alarmingly is that the supplies of fossil energy resources is limited and decreases in the face of the increased demand for energy. Considering the negative impact of fossil energy sources on the environment together with the scarcity of these resources, it appears urgent and very important to find new energy resources that are clean and renewable. Wind energy is; therefore, very important as one of these clean energy resources. Wind rotors are the most important tools of the wind energy. One of the wind rotors of a vertical axis is the Savonius wind rotor. It is simple in structure, cheaper, has good starting characteristics, relatively low operating speeds, and an ability to capturing wind from any direction. But it has a low aerodynamic efficiency. It is constructed simply of two vertical half cylinders, as shown in Fig. 1.

The ratio between rotor height $\mathrm{H}$ and rotor diameter $\mathrm{D}$ is called the aspect ratio $\alpha$. Another parameter that affects the performance of Savonius rotor is the overlap ratio $\beta$ which is expressed as: $\beta=(e-a) / d$; where $\mathrm{e}$ is the over lap, a is the shaft diameter and $\mathrm{d}$ is the blade diameter.

Performance of the Savonius rotor has been studied by many researchers from 1977 until 2010 in order to determine the optimum design parameters of this rotor.

Effect of blade aspect ratio, blade overlap and gap besides effect of adding end extensions, end plates and shielding were tested by Alexander and Holownia [1]. They concluded that, there is an improvement in rotor performance with increasing the aspect ratio. The tests for three and four bladed geometries gave appreciably lower values of efficiency than two blades rotor. They use four values of extensions and find that the efficiency increases with the increase of the extension. They concluded also that the efficiency for the rotor with end plate and shielding is greater than that with end plate and without shielding. Furthermore, the efficiency obtained for a rotor with end plate and without shielding is greater than that of rotor without end plate. They found also that, increasing the rotor over lap ratio rises the rotor efficiency. Modi et. al. [2] reported that the optimum values of aspect and over lap ratios are 0.77 and 0.25 respectively. Mojola [3] concluded that the effect of over lap ratio on rotor performance depends on its tip speed ratio. Nobuyuki [4] investigated the aerodynamic performance and the flow fields of Savonius rotors at various overlap ratios. The static torque performance of the rotor, specially of the returning blade, is improved by the presence of the overlap and the best value was found to be 0.15 . Menet [5] constructed a prototype of Savonius turbine to charge a battery. He utilized a rotor with aspect ratio of 4 and over lap of 0.25 . He found that starting velocity was $3 \mathrm{~m} / \mathrm{s}$, velocity for maximum production is $13 \mathrm{~m} / \mathrm{s}$ and the mean efficiency between 5 and $10 \mathrm{~m} / \mathrm{s}$ was found to be $29 \%$. The range of rotational speed was 200 to 800 rpm. Kamoji et. al. [6] examined helical Savonius rotors in an open jet wind tunnel. From their results the helical rotors with shaft have lower power coefficient than the helical rotors without shaft. Saha et. al. [7] carried out a comparison between savonius rotor with different geometries. They reported that, the optimum number of blades is two for Savonius rotor whether it is single-, two- or three-stages. Twisted geometry of blade profile has a good performance as compared to the semicircular blade geometry. Two-stages Savonius rotor has better power coefficient as compared to the singleand three-stage rotors. Altan et. al [8] studied the curtain arrangement using two plates, one in the upper end of rotor and the second at the rotor lower end. This arrangement is used to prevent the air leakage from the concave side. They concluded that the arrangement increases the rotor performance. They used three curtaining arrangements by changing the two plate lengths and the angle on the horizontal axis. The results showed that the curtaining which has longest plates is the better and the optimum angel is $15^{\circ}$ on the horizontal axis for the upper plate and $45^{\circ}$ for the lower one. Altan et. al. [9] made a comparison between the measurements and the numerical results. Gupta et. al. [10] made a combination between Savonius wind rotor and Darrieus wind rotor. They compared the results obtained with those of conventional Savonius rotor. They observed that there is a retable improvement in the power coefficient for the combined Savonius-Darrieus rotor. Kamoji et. al. [11] studied the effect of the overlap ratio, blade arc angle, aspect ratio and Reynolds number on the performance of Savonius rotor. They found that, the modified Savonius rotor without overlap ratio, with blade arc angle of $124^{\circ}$ and with an aspect ratio of 0.7 has a maximum power coefficient of 0.21 at Reynolds number of 150000 . The obtained value of the power coefficient is higher than that of conventional Savonius rotor. Roth [12] tested the effect of both aspect ratio and over lap ratio. He 
reported that the best values are as 0.77 and 0.22 respectively. Blackwell et. al. [13] reported that the two-stages geometry have better aerodynamic performance than the three-stage one, with the exception of starting torque. They decided also that, the increase in aspect ratio improving the rotor performance. Shankar [14] tested both two-blades and three-blades geometries. He found that, twobladed Savonius rotors have almost $50 \%$ higher peak power output than the three-bladed rotors. Mahamarakkalage [15] examined experimentally and analytically blade geometry, overlap ratio, aspect ratio and Reynolds number on Savonius rotor performance. The results showed that optimum geometries of Savonius rotor are as follows: gape size of 0 , over lap ratio of 0 , aspect ratio of 0.77 , blade shape parameter of 0.2 and blade arc angle equals $135^{\circ}$. The rotor with the previous configuration will have a peak power coefficient of about 0.32 at tip-speed ratio of 0.79 .

The above researches on Savonius rotors give different optimum geometries and therefore more studies are needed to determine the optimum configuration of Savonius rotor. In [16] various configurations of Savonious rotors concerning number of blades, number of stages, overlap ratio, aspect ratio and existence of rotating or fixed end plates are studied experimentally to determine the optimum configuration of Savonius rotor which gives the higher performance. This experimental study was carried in Fluid Mechanics Laboratory at Mechanical Power Engineering Department, Faculty of Engineering, Shebin El-Kom, Menoufiya University.

The aim of this work is to design and test a prototype of Savonius rotor in free wind based on the results of the previous experimental study. The prototype is designed and tested in El-Arish at the Faculty of Engineering, Sinai University.

\section{EXPERIMENTAL PROGRAM}

\subsection{Construction of the Prototype}

In order to apply the results of the measurements executed on different Savonius rotor models at Fluid Mechanics Laboratory, Mechanical Power Engineering Department, Faculty of Engineering, Menoufiya University, it is important to design and test a prototype in free wind. The prototype is designed according to the optimum configurations obtained from the experimental results [16]. The prototype is constructed in El-Arish at the Faculty of Engineering, Sinai University. The complete view of the Savonius rotor prototype is shown in Fig. 2.

The choice for blade material was obviously important. Different criteria were considered for this choice: low price, building easiness, low weight, good resistance to outside elements (humidity, temperature variation, etc.) and good rigidity. Instead of metals, it is decided to use fiber glass. The thickness of the blade should be low as possible to reduce its weight but in the range to able to be rigid.

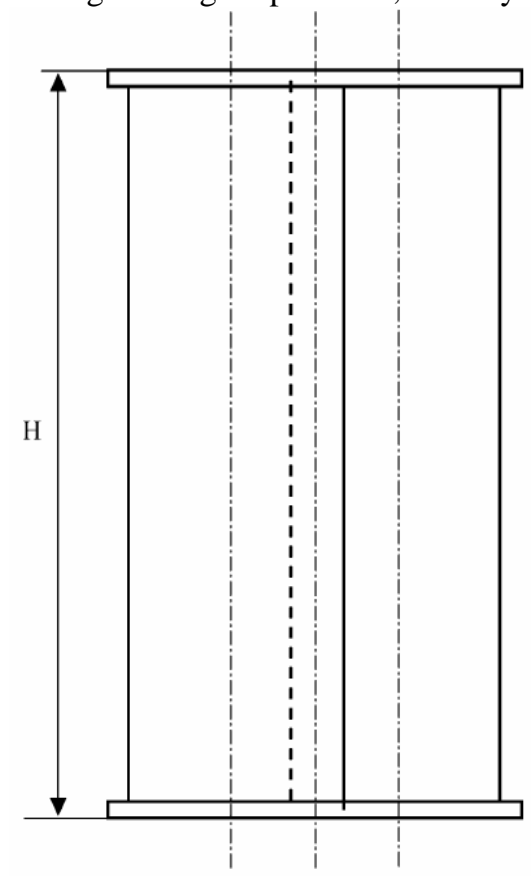

(a)

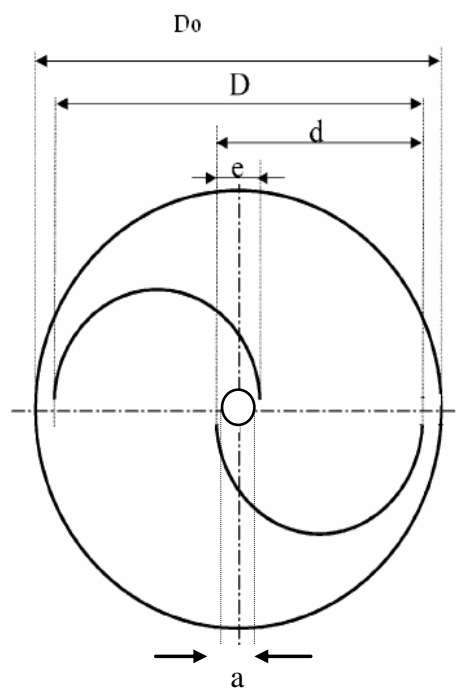

(b)

Fig. 1 Scheme of a single-stage Savonius rotor: (a) elevation view; (b) plane view 


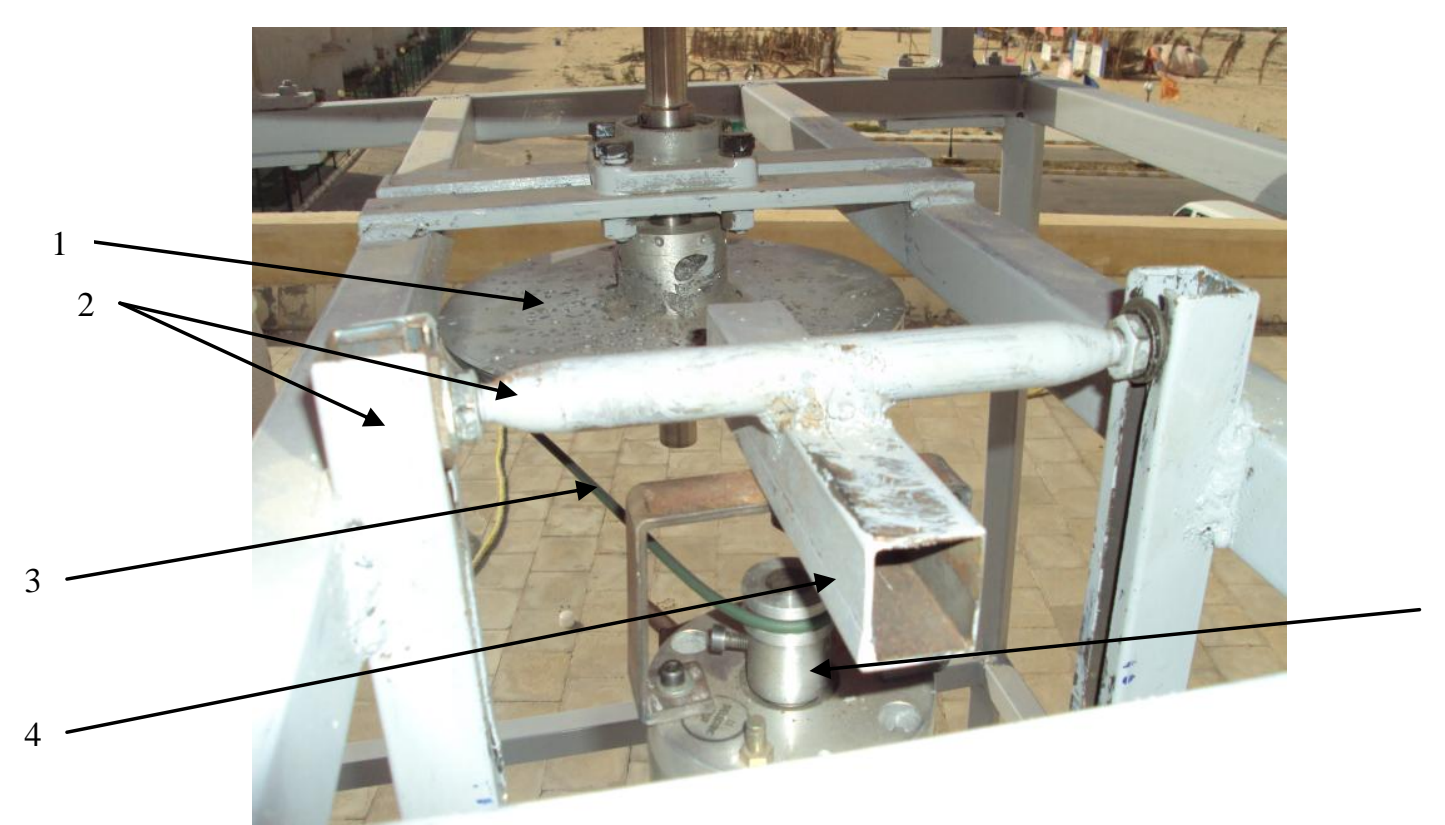

Fig. 2 Photograph for the present Savonius rotor prototype.1- Savonius blade, 2- steel housing, 3- generator, 4SKF-bearing and 5- stainless steel shaft

Only the ends of the blades rotor are $6 \mathrm{~mm}$ to be good rigid to the bolts which fixed it in the shaft. The middle area has $3 \mathrm{~mm}$ thickness. The ratio between blade height to blade length (aspect ratio) is chosen as 3.33 for this prototype with blade height about 2 $\mathrm{m}$ and rotor diameter about $0.6 \mathrm{~m}$. The prototype is constructed as two blades, without overlap and single stage rotor in future another stages can be added.

The shaft diameter is chosen as $25 \mathrm{~mm}$ to ensure save loading of the shaft. The choice of the length based on the rotor height, where the rotor height is 2 $\mathrm{m}$ for single stage the shaft length is $220 \mathrm{~cm}$ between the two bearings, $15 \mathrm{~cm}$ length down the lower bearing to connect the generator on it and $15 \mathrm{~cm}$ up the upper bearing to connect the shaft for double stages in the future. The total length of the shaft is about $2.5 \mathrm{~m}$. The shaft has been made from a stainless steel bar.

The bearings is exposed to dust and humidity because they are obviously designed to be used outside. These bearings must run continuously for a few thousands of hours and they must support mechanical stresses due to the weight of the rotor, the centrifugal forces, and the drag of the rotor (especially in case of drastic wind velocity distributions). The criteria leads to choose SKF-ball bearings. The inner diameter of the bearing must 25 $\mathrm{mm}$ to be exactly connected with the shaft without any vibration.

The end plate is preferred to be from the same material of the rotor blades to have the same advantages, and its diameter is taken as 1.1 of the rotor diameter (i.e. about $68.5 \mathrm{~cm}$ ).

Savonius rotor is considered law speed rotor and it is better to use this rotor for mechanical power generation. But for the purpose that the output of the prototype is sensible, the mechanical power is converted to electrical power. It was decided to use a permanent magnet generator. The electrical power of this generator is about $80 \mathrm{~W}$. Permanent magnet generator have in fact many advantages, mainly their low price and high reliability. However, this generator runs and correctly produces electricity at any rotational speed and its power depends on number of revolutions.

To increase the number of revolutions reaching to generator, the pulleys with diameter ratio (10 to 1 ) is used on rotor and generator shafts. The diameter of the pulley on the shaft is $260 \mathrm{~mm}$ and on the generator is $26 \mathrm{~mm}$. These pulleys were made from aluminum and fabricated by casting and was finished on the lathe. The connection between the two pulleys was made by a ring belt. To adjust the belt between the two pulleys, a mechanical mechanism was used to allow the movement of the generator horizontally and vertically as shown in Fig. 3 .

The housing to carry the rotor should be rigid to ensure the safety from vibrations and stresses. The housing was constructed from a square cross sectional steel duct with $4 \times 4 \mathrm{~cm}$ cross section. The housing must be larger than the rotor diameter to facilitate air arriving to the rotor from all directions.

\subsection{Power Output from Savonius Rotor Prototype}

The load connected on the generator output comprises lamps in series or a battery. After battery charging its power can be used as required. The second connection is the preferred one because the power requirement is not all the time. Figure 4 shows the connection of lamps in series and battery for charging. The generator output voltage varied from 0 to $60 \mathrm{DC}$ voltages. In the second connection the 
positive line of the battery is connected with the positive line of the generator and the same in the negative line. First the battery is empty and with this connection the battery will charge to any value. At law wind speed the output power will decrease, in this case the battery will drive the generator as a motor loaded on the battery. To prevent the fly back current from the charged DC battery to the generator, control switch unidirectional (silicone diode) is put between the generator and battery, connect the anode with the positive line of the generator and the cathode to the positive line of the battery, the circuit is shown in Fig. 4-b. Based on the load connected to the battery, if the load is DC, it is connected to the battery directly but if the load is AC, DC to AC converter must be used between the battery and the load.

\subsection{Measurement Procedures and Computational Parameters}

The output power from prototype is measured along the day for different several days. The wind speed is measured by a propeller type digital anemometer. The output power is measured mechanically or electrically. The electrical power output from Savonius rotor prototype can be determined as

$$
P_{E}=V I
$$

where $\mathrm{V}$ is the output voltage and $\mathrm{I}$ is the output current which are measured by multimeter.

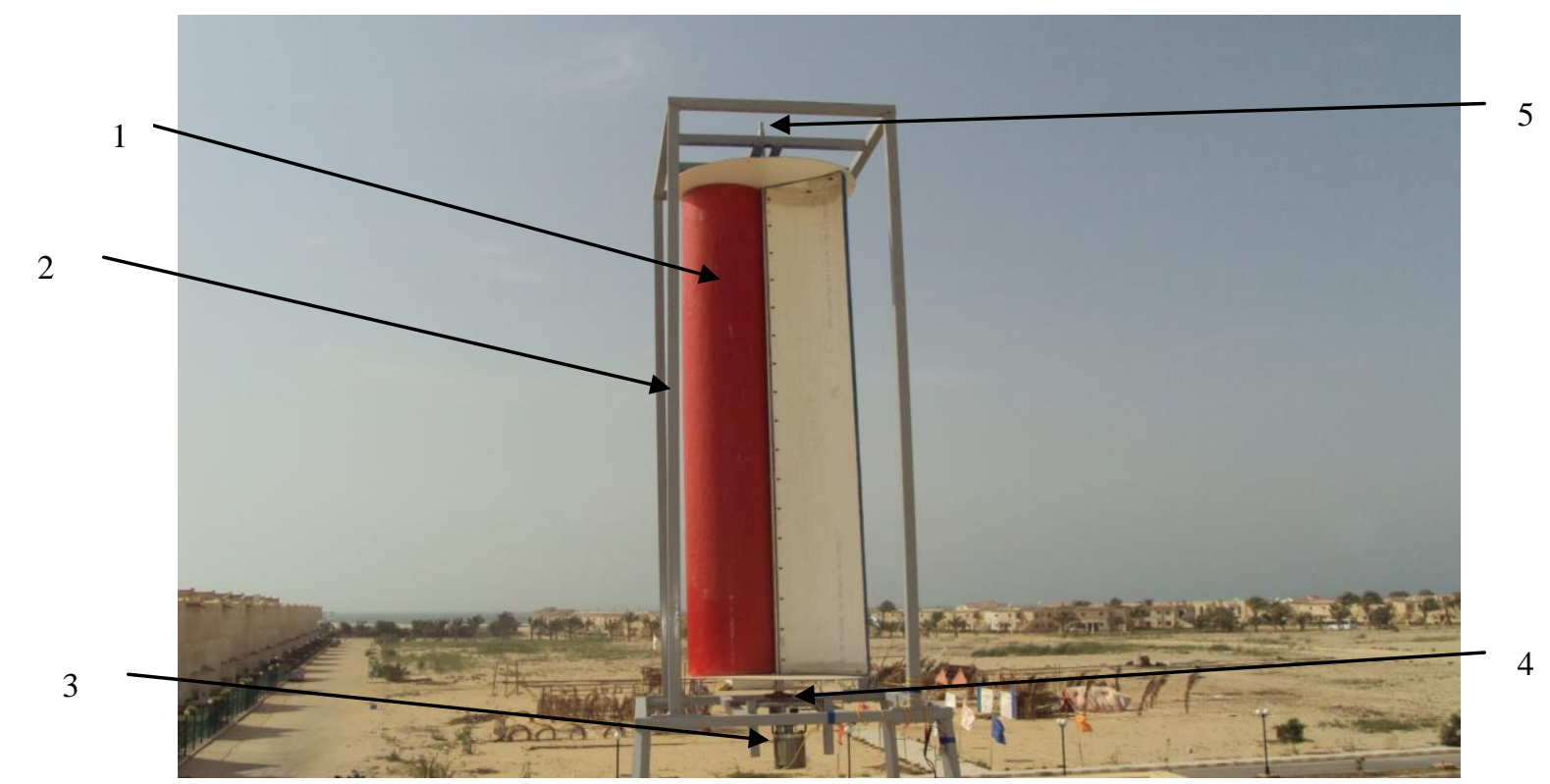

Fig. 3 Photograph for shafts connection, 1- shaft pulley, 2- vertical displacement mechanism, 3- round belt, 4horizontal displacement mechanism and 5- generator pulley

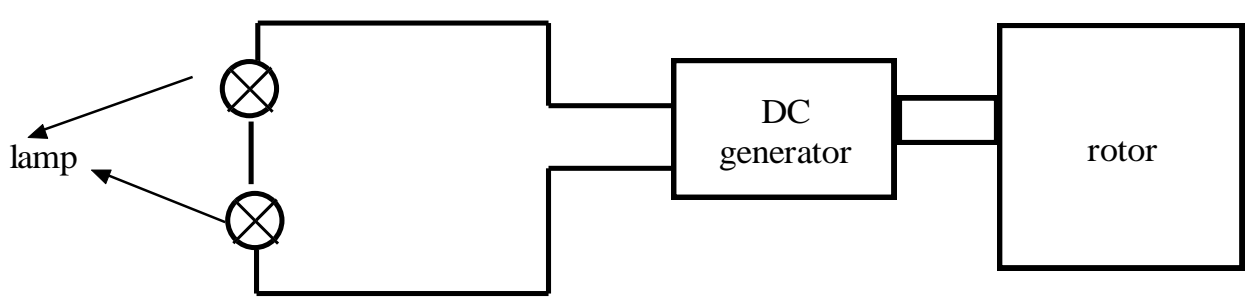

(a) lamps in series

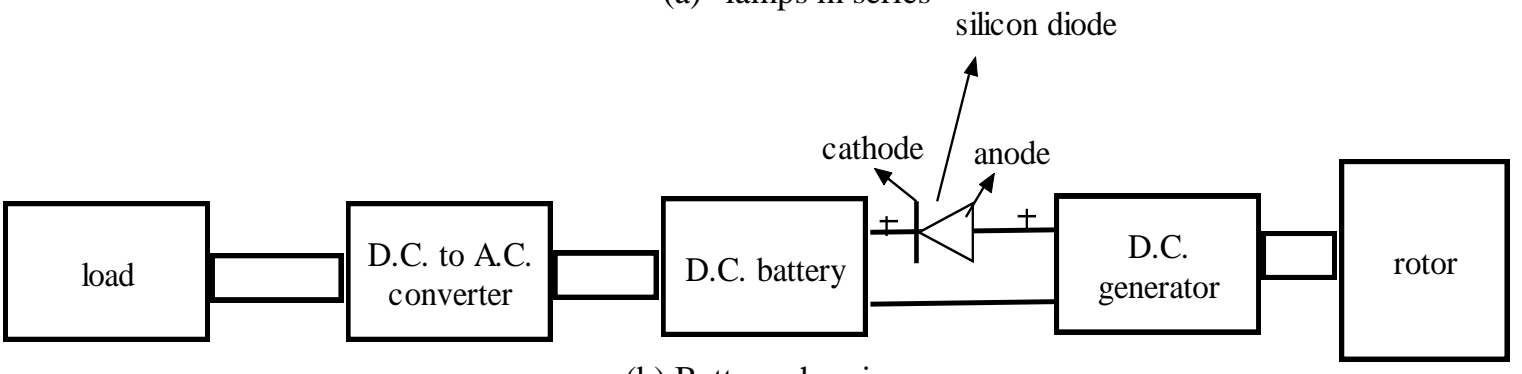

(b) Battery charging

Fig. 4 Schematic diagram for power output from Savonius rotor 
The mechanical power for the tested Savonious rotor is determined by measuring both the mechanical torque and rotational speed on the rotating shaft. The arrangement used for measuring the mechanical torque is shown in Fig. 5. It contains pulley system, nylon string, weighing pan and spring balance. The weighing pan, pulleys and spring balance are connected by a nylon string of $1 \mathrm{~mm}$ diameter. The shaft rotational speed is measured using a digital DC tachometer.

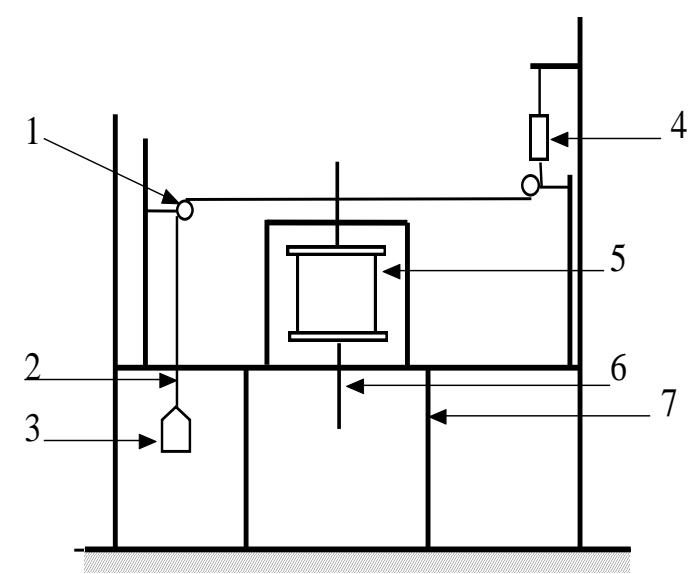

Fig. 5 Schematic diagram of Savonius rotor connected with mechanical torque measurement arrangement, (1: pulley; 2: nylon string; 3 : weighing pan; 4: spring balance; 5 : Savonius rotor; 6 : rotating shaft and 7: structure)

From the measured values of mechanical torque and rotational speed, the mechanical power is estimated at each wind speed as:

$$
P_{m}=T \omega
$$

where $\mathrm{T}$ is the mechanical torque and $\omega$ is the angular speed.

The angular speed is defined in $\mathrm{rad} / \mathrm{sec}$ as:

$$
\omega=\frac{2 \pi n}{60}
$$

where $\mathrm{n}$ is the shaft rotational speed in rpm.

The mechanical torque is obtained in (N.m) by

$$
T=F r
$$

where $r$ is the pulley radius

The force acting on the rotor shaft $\mathrm{F}$ is obtained in (N) from the following relation:

$$
F=(m-s) g
$$

where $\mathrm{m}$ is the mass loaded on the pan in $\mathrm{kg}$, $\mathrm{s}$ is the spring balance reading in $\mathrm{kg}$ and $\mathrm{g}$ is the gravitational acceleration.

The power coefficient $\mathrm{C}_{\mathrm{p}}$ can be determined using the following equation:

$$
C_{P}=\frac{P_{m}}{P_{w}}
$$

The efficiency of the prototype can be formulated as

$$
\eta_{t}=\frac{P_{E}}{P_{w}}=\frac{V I}{0.5 \rho A u_{1}^{3}}
$$

where $\mathrm{u}_{1}$ is the undisturbed wind speed.

From the measured data, the daily average wind speed and average power can be obtained. The energy obtained from Savonius rotor prototype is determined as

$$
E=P_{\text {ave }} . t i m e
$$

The expected cost of kw hr obtained from Savonius rotor prototype can be obtained from

$$
\cos t / k w h r=\frac{\text { total } \operatorname{cost}}{\text { total } \text { Energy }}
$$

where total cost is the total prototype cost and total energy is the total energy produced from prototype through its expected life. The total prototype cost is about $1000 \mathrm{LE}$ and its expected life span is estimated to be 20 years.

\section{RESULTS AND DISSCUSSION}

Figure 6 shows the change of wind speed with time in El-Arish on 27.06.2010. The average wind speed in this day was $4.03 \mathrm{~m} / \mathrm{s}$. The variation in mechanical power with time for this day is shown in Fig. 7. The maximum mechanical power obtained from the prototype for this day is recorded at the hour 21 and it is about 85 Watt. From these curves one can see that the mechanical power is depended mainly on wind speed in location. The mechanical power and wind speed reach their maximum values in this day at about the hour 21. The average power in this day can be estimated as 17.012 Watt. The total energy produced in this day is expected to be 408.29 Watt hr/day. Figure 8 shows the change in mechanical power with wind speed for this day, while the variation in power coefficient with tip speed ratio is presented in Fig. 9. The increase in wind speed results in gross increase in mechanical power. The power coefficient reaches its maximum value of about 0.3 at tip speed ratio of about 1 .

The tests on Savonius rotor prototype are achieved in several days in Juni, Juli, August and September 2010. The variation in average mechanical power with average wind speed for some days of the measurements is given in Fig. 10. Figure 11 presents the change in power coefficient with tip speed ratio for some days. The days with higher average wind speed having also higher mechanical power and higher power coefficients. 


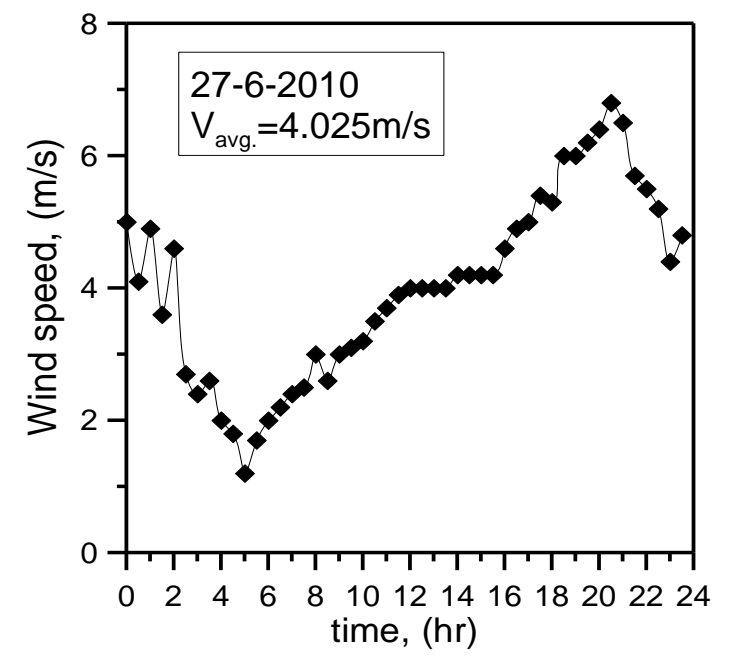

Fig. 6 Measured wind speed along the day in ElArish on 27.06.2010

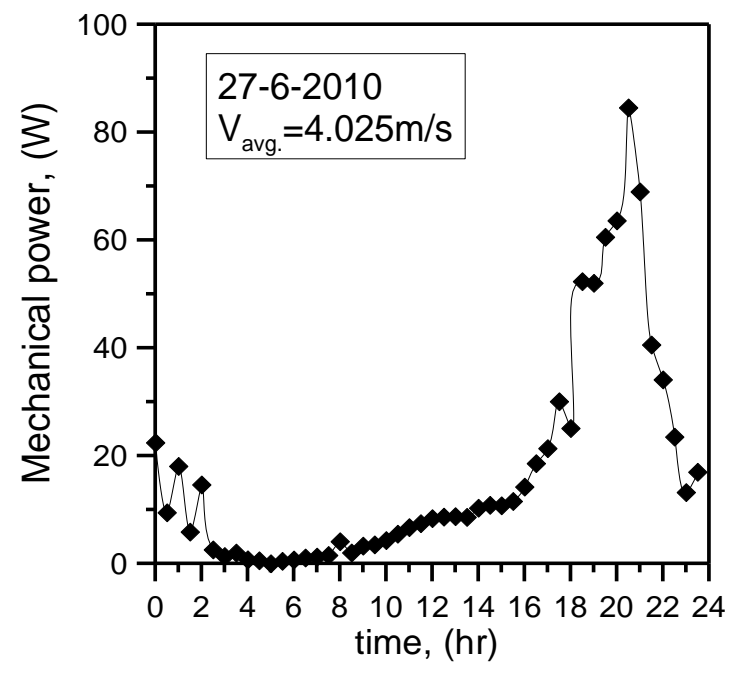

Fig. 7 Measured mechanical power along the day on 27.06.2010

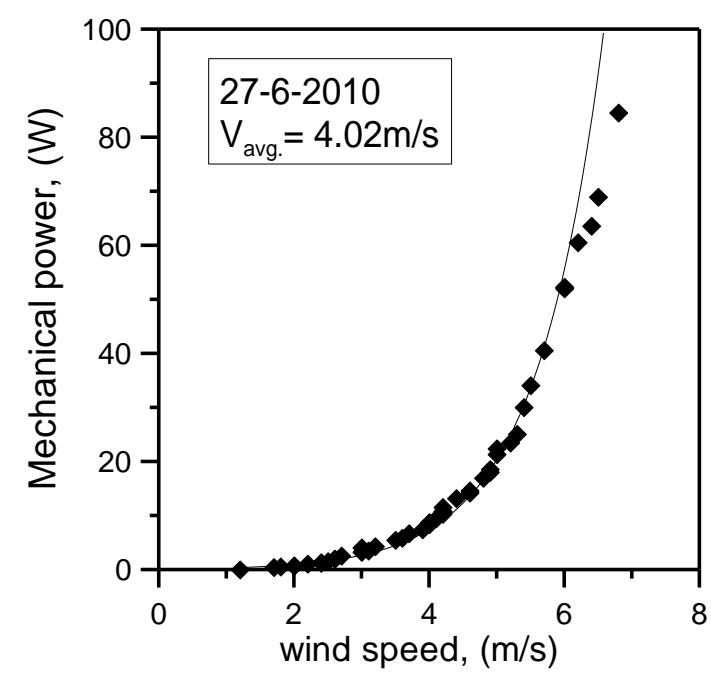

Fig. 8 Variation of mechanical power with wind speed for the Savonius prototype on 27-6-2010

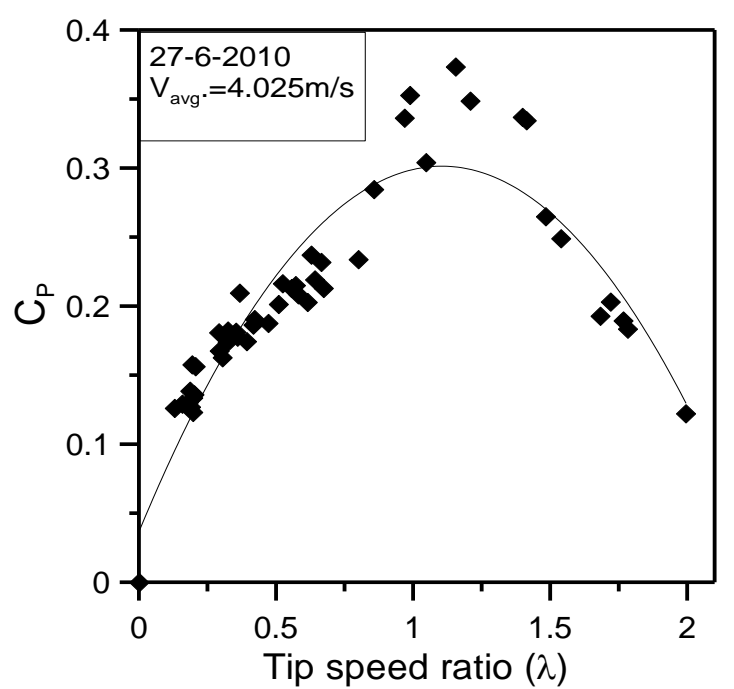

Fig. 9 Variation of power coefficient with tip speed ratio for the Savonius prototype on 27-6-2010

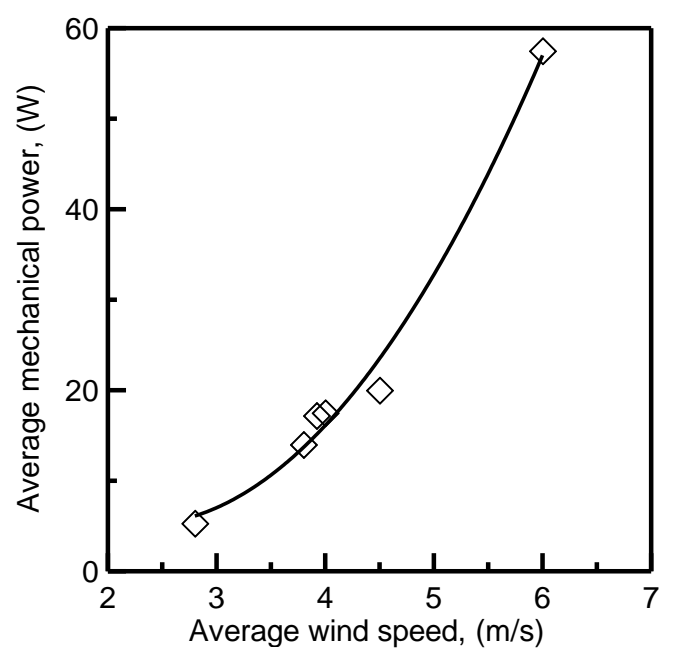

Fig. 10 Variation in mechanical power with wind speed for different days of measurements

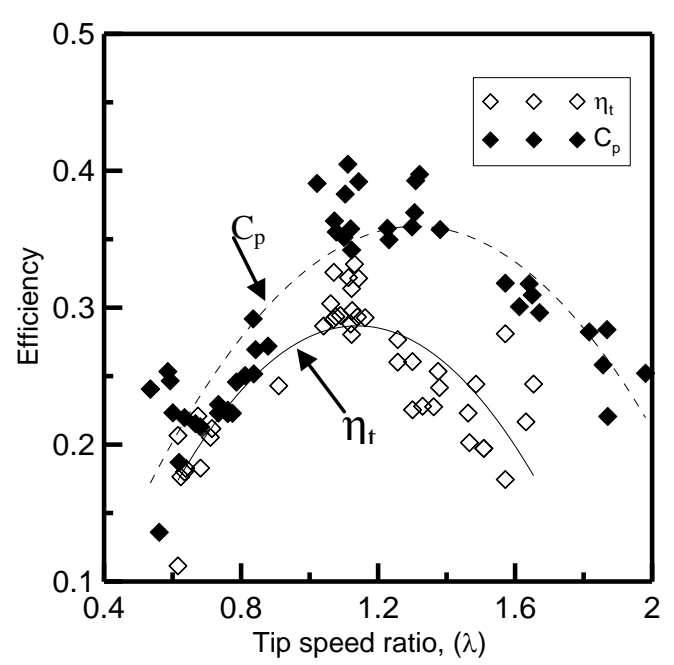

Fig. 11 Relation between power coefficient and tip speed ratio for the Savonius prototype at different average wind speeds 
Figure 12 indicates the variation of both electrical and mechanical power output with wind speed. It is seen that the mechanical power is higher than the electrical power at the same value of wind speed and the start wind speed for mechanical power is lower than start wind speed for electrical power. Figure 13 declares the change of prototype efficiency and power coefficient with tip speed ratio. The prototype efficiency has been also shown lower than its power coefficient due to the losses consumed in conversion of mechanical power to electrical one.

The energy generated from Savonius rotor prototype in the several days of the measurements is computed and shown in Fig. 14. The energy generated depends mainly on wind condition in location along the day.

The average yearly wind speed in El-Arish is about $2.79 \mathrm{~m} / \mathrm{s}$ [17]. This is considered as a low wind speed location compared to another locations with higher average wind speed (e.g. Hurghada). The results show that Savonius rotor prototype in ElArish gives considerable efficiency and begins to give power at a relative low wind speed.

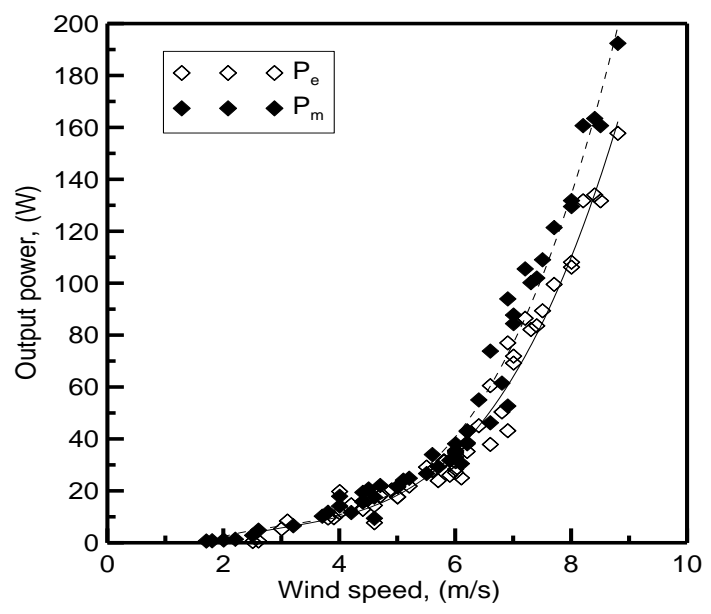

Fig. 12 Variation of electrical and mechanical power with wind speed at 27.06.2010

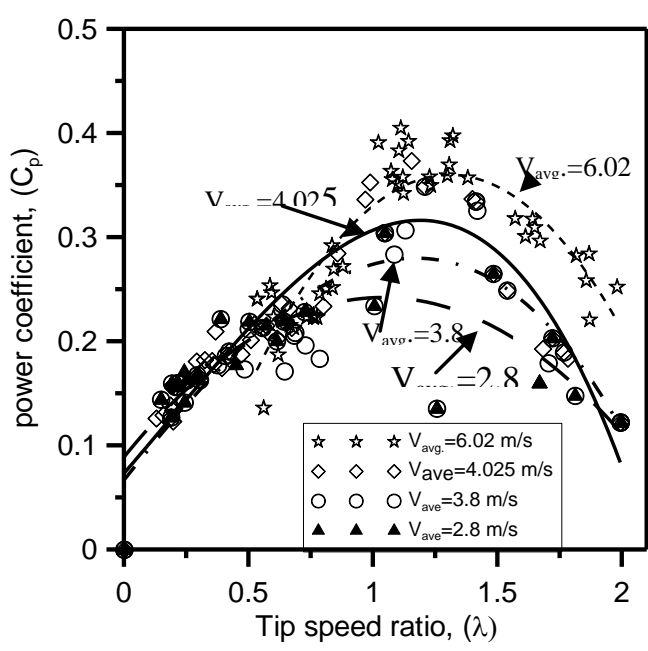

Fig. 13 Change of prototype efficiency and power coefficient with tip speed ratio

Table 1 summarizes the average wind speed, average power, energy generated per year and the cost of $\mathrm{kW}$ $\mathrm{hr}$ for the days of the measurements. It is seen here that, the cost of $\mathrm{kW} \mathrm{hr}$ decreases with the increase in average wind speed. The cost of $\mathrm{kW}$ hr generated from the Savonius rotor prototype in El-Arish will be about $0.1 \mathrm{LE}$ when the average wind speed is $6 \mathrm{~m} / \mathrm{s}$.

Table 1, Summary of the average wind speed, average power, energy generated per year and the cost of $\mathrm{kW} \mathrm{hr}$ for the days of the measurements

\begin{tabular}{|l|l|l|l|l|}
\hline Date & $\begin{array}{l}\mathbf{u}_{\text {ave, }} \\
\mathbf{m} / \mathbf{s}\end{array}$ & $\begin{array}{l}\mathbf{p}_{\text {ave }}, \\
\text { Watt }\end{array}$ & $\begin{array}{l}\text { Energy, } \\
\text { W hr/ } \\
\text { year }\end{array}$ & $\begin{array}{l}\text { Cost, } \\
\text { LE/kW } \\
\text { hr }\end{array}$ \\
\hline 27.06 .2010 & 4 & 17.5 & 148993 & 0.326 \\
\hline 28.06 .2010 & 4.5 & 20.2 & 152023 & 0.285 \\
\hline 29.06 .2010 & 3.9 & 17.2 & 152022 & 0.33 \\
\hline 03.07 .2010 & 3.8 & 14 & 129064 & 0.407 \\
\hline 02.08 .2010 & 2.8 & 5.3 & 41136 & 1.07 \\
\hline 25.09 .2010 & 6 & 57.5 & 504065 & 0.099 \\
\hline
\end{tabular}

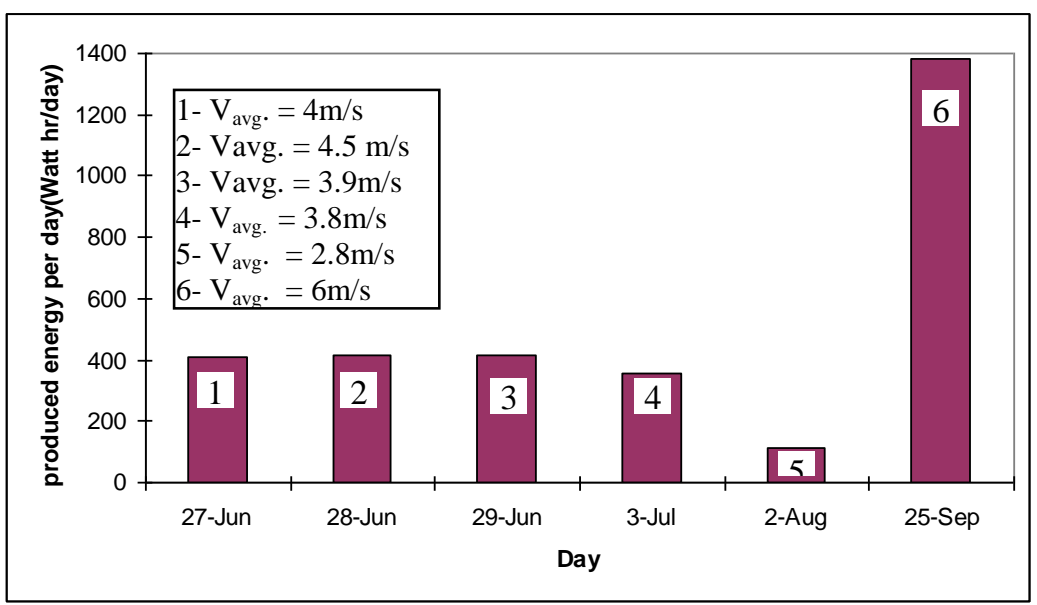

Fig. 14 Energy generated from Savonius rotor prototype in the several days of the measurements 


\section{CONCLUSIONS}

In this work a Savonius rotor prototype is designed, fabricated and tested in free wind. The design of this prototype is based on the previous experimental measurements which achieved in Advanced Fluid Mechanics Laboratory at Mechanical Power Engineering Department, Faculty of Engineering, Shebin El-Kom, Menoufiya University. The prototype is constructed in El-Arish at the Faculty of Engineering, Sinai University.

Although El-Arish has lower average yearly wind speed compared to another locations with higher average wind speed, like Hurghada. The results show that, Savonius rotor prototype works in free wind with a considerable efficiency. It begins to give power at a relative low wind speed. The output energy from Savonius rotor is relatively small because of the efficiency of Savonius rotor is smaller than high speed horizontal axis wind turbines. But the cost of energy unit is also small and competitive with other energy sources due to the lower cost of construction.

The use of Savonius rotor will be attractive in many locations in Egypt. The cost of kW.hr generated from Savonius rotor is expected to be very low specially in locations with high average wind speed. The majority of Egyptian locations having an average wind speed between 3.5 and $4.5 \mathrm{~m} / \mathrm{s}$. The cost of kW.hr generated from Savonius rotor in these locations is expected to be between 0.28 and 0.42 LE. In locations where average wind speed is $6 \mathrm{~m} / \mathrm{s}$, the cost of $\mathrm{kW} . \mathrm{hr}$ is expected to be $0.1 \mathrm{LE}$.

Therefore Savonius rotor can be used in the majority of the Egyptian locations, for example, to pump water for irrigation of land. This will save a great part of conventional energy sources used for this purpose and consequently reduces the environmental pollution.

\section{REFERENCES}

[1] Alexander, A. J. and Holownia, B. P., "Wind tunnel tests on a Savonius rotor", Journal of Industrial Aerodynamics, 3 (1978), pp 343-351

[2] Modi, V.J; Roth, N.J. and Fernando, M.S., "Optimum-configuration studies and prototype design of a wind-energy-operated irrigation system", Journal of Wind Engineering and Industrial Aerodynamics, 16 (1984), pp 85-96

[3] Mojola, O., "On the aerodynamic design of the Savonius windmill rotor", Journal of Wind Engineering and Industrial Aerodynamics, 21 (1985), pp 223-231

[4] Nobuyuki, F, "On the torque mechanism of Savonius rotors", Journal of Wind Engineering and Industrial Aerodynamics, 40 (1992), pp 277-292
[5] Menet, J.L., "A double-step Savonius rotor for local production of electricity", Renewable Energy 29 (2004), pp 1843-1862

[6] Kamoji, M.A.; Kedare, S.B. and Prabhu, S.V., "Performance tests on helical Savonius rotors", Renewable Energy, 34 (2008), pp 521-529

[7] Saha, U.K.; Thotla, S. and Maity D., "Optimum design configuration of Savonius rotor through wind tunnel experiments", Journal of Wind Engineering and Industrial Aerodynamics, 96 (2008), pp 1359-1375

[8] Altan, B D. and Atılgan, M., "An experimental study on improvement of a Savonius rotor performance with curtaining", Experimental Thermal and Fluid Science, 32 (2008), pp 16731678

[9] Altan, B D. and Atılgan, M., "An experimental and numerical study on the improvement of the performance of Savonius wind rotor", Energy Conversion and Management, 49 (2008), pp 3425-3432

[10] Gupta, R., Biswas, A.and Sharma, K.K., "Comparative study of a three-bucket Savonius rotor with a combined three-bucket Savoniusthree-bladed Darrieus rotor", Renewable Energy, 33 (2008), pp 1974-1981

[11] Kamoji, M.A.; Kedare, S.B. and Prabhu, S.V., "Experimental investigations on single stage modified Savonius rotor", Applied Energy, 86 (2008), pp 1064-1073

[12] Roth, N. J., "Prototype designe and performance of Savonius rotor based on irrigation system", a thesis of master degree, University of Britich Columbia, 1982.

[13] Blackwell, B. F.; Sheldahl, R. E. and Feltz, L. V., "Wind tunnel performance data for two- and three-bucket Savonius rotors", Thesis Issued by Sandia Laboratories, July 1977.

[14] Shankar, P. N., "Development of vertical axis wind turbines", Proc. Indian Acad. Sci., Vol. C 2, Pt. 1, March 1979, pp. 49-66.

[15] Mahamarakkalage, F., "On the performance and wake aerodynamics of the Savonius wind turbine", a thesis of Doctoral Philosophy, University of Peradenyia, Sri lanka (1980).

[16] Mahmoud, N. H.; El-Haroun, A. A.; Wahba E. and Nasef, M., "An experimental study on improvement of Savonius rotor performance", under publication.

[17] Wind Data Obtained From The Egyptian Meteorological Authority, 1989. 